\title{
La construcción de lo guay en lo urbano. El caso de las Condesas de la Ciudad de México
}

Construction of Cool in Urban Places. The Case of Condesas in Mexico City

Luis A. GonZÁlez-ArenAL Puebla Ciudad Creativa del Diseño de Unesco Red de Ciudades del Aprendizaje de Unesco

Resumen: El artículo analiza un fenómeno de revitalización urbana en áreas centrales de la Ciudad de México provocada por la visión de creativos que ven en estos barrios una gran oportunidad de tener su vivienda y su trabajo en una ubicación central de la ciudad, aprecian a la ciudad caminable y al atractivo de una sección de una ciudad que acoge y da la bienvenida a todas las tribus urbanas. ¿Es lo cool o guay como fenómeno, un detonador de la revitalización de estas zonas centrales de la ciudad? ¿Se puede construir lo guay? ¿Son Chueca en Madrid, Carlton en Melbourne, Le Marais en París, Islington en Londres, Below 14 ${ }^{\text {th }}$ Street en Manhattan o Gas Town en Vancouver casos análogos a las Condesas o tendrán por lo menos puntos en común? 
Palabras clave: revitalización urbana, ciudad central, guay, cool, creativos, economía, ciudad creativa, barrios centrales, tendencias.

Abstract: This article analyses an urban revitalization phenomenon in central areas of Mexico City pushed by the vision of creatives that see in these neighbourhoods a big opportunity to have their living and working spaces close to each other in a privileged location in the city. Creatives of all kinds value the walkable city, its location and the convenience of living in an area of the that welcomes diversity and all kinds of urban tribes. Is cool a tool for detonating revitalization in under used urban neighbourhoods? Can cool be produced? Are Carlton in Melbourne, Le Marais in Paris, Islington in London, Below $14^{\text {th }}$ Street in Manhattan or Gas Town in Vancouver similar to what is going on in Mexico City Condesas, could they have things in common?

Keywords: urban revitalization, central city, cool, creatives, economy, creative city, central neighbourhoods, trending.

Fecha de recepción: 6/4/2021

Fecha de aceptación: 9/8/2021 
En muchas de las grandes urbes sigue vigente una abrumadora tendencia de ampliar los límites y de seguir poblando las periferias con nuevos desarrollos, pero también podemos encontrar que centralidades que sufrían deterioro y falta de atención de improviso se convierten en las protagonistas de la revitalización y se vuelven el foco de atención de propios y extraños.

Los desarrollos inmobiliarios de la periferia son generalmente los actores principales del gran aparato mercadotécnico y provocan un efecto de neblina que no permite ver las bondades de descubrir, o redescubrir en algunos casos, las áreas centrales de la ciudad. Por otro lado la facilidad de desarrollar una promoción inmobiliaria especializada y homogénea, ya sea esta de vivienda, industria o de comercios, no implica los retos de esta misma actividad pero inmersa dentro del marco de la centralidad con su mucha o poca complejidad y con las presiones que sus cambios ejercen en la vida de la ciudad. Este último comentario se refiere a que los cambios en la ciudad central repercuten en las periferias igual que en sentido inverso.

¿Quiénes son los agentes y actores que provocan esta vuelta a poner en escena de una zona determinada y que provocan cambios importantes dentro de esta y paralelamente influyen en el resto del área urbana?

Para estudiar este fenómeno y para tratar de contestar el cuestionamiento anterior he escogido un caso muy reciente y en muchos sentidos excepcional de revaloración del territorio en la ciudad de México; los barrios de la Condesa, Hipódromo e Hipódromo Condesa de la ciudad de México. Todas ellas colindantes la una con la otra y ubicadas en la zona central de la ciudad al 
suroeste del casco histórico metropolitano, son una producción inmobiliaria del primer tercio del siglo xx y alojan a las primeras emigraciones que salen del casco histórico y se ubican en la entonces periferia de la ciudad.

Estas tres colonias ${ }^{1}$ que datan en el caso de la Condesa de principios del siglo xx y en el de la Hipódromo e Hipódromo Condesa de los años treinta del mismo siglo, están actualmente en el centro de la vida social e inmobiliaria de la ciudad de México y han tenido en los últimos diez años un auge excepcional que se ha reflejado en los valores de la tierra mismos que a la fecha compiten en valor de venta con zonas residenciales altamente comerciales de la ciudad de México tales como Santa Fe, Polanco y Bosques de las Lomas.

Se da en estos barrios de la centralidad una emulación del estilo europeo de vivir contra un apabullante avance del american way of life prevaleciente en prácticamente todas las ciudades del país.

Este documento trata en un primer momento de esbozar algunas consideraciones sobre el concepto de lo cool para tratar de aclarar los puntos a desarrollar en este documento y que son medulares para entender la forma en la que estas zonas centrales han recuperado y en muchos casos adquirido una nueva vitalidad.

¿Será esta una condición posible de provocar, hay factores que la detonan o se produce espontáneamente? ¿Puede ser que lo guay sea donde se intersectan la ciudad tradicional con su carga de significados y su territorio con su capacidad de adaptación con lo joven, lo nuevo y lo actual para producir la ciudad que nos imaginamos? ¿Es lo guay una fuerza atrás de esta vitalidad y de esta revaloración del espacio urbano?

1 La palabra latina «colonia» que significaba para los romanos «conjunto de personas que van de un lugar a otro a poblarlo y cultivarlo» y que sirve para denominar asentamientos, territorios, poblados, etc., se aplicó en México para indicar las zonas o los barrios donde se asentaban los diferentes grupos de extranjeros que vivían en el país. 
La construcción de lo guay en lo urbano.

En esta misma perspectiva me detengo a analizar los antecedentes y el contexto de la creación de estas primeras periferias o fraccionamientos extramuros que son ahora territorios que podríamos denominar «suburbios interiores» y que con el crecimiento de la ciudad son parte ya de la centralidad de esta inmensa zona metropolitana.

Como parte importante para ubicar mentalmente este estudio en el espacio urbano, se describe el escenario donde estos agentes y actores se desenvuelven y se analiza la posible causalidad de este resultado urbano que sirve ahora de plantilla para alojar un sinnúmero de actividades que conviven, no sin conflictos pero sí con una gran fuerza de cohesión y de un gran poder de convocar a personas con diferentes tipos de intereses. Este estatus conflictual y complejo de la ciudad, que es parte de su vida y razón de ser como producto social, me anima a definir al espacio urbano como un producto vital con sustento territorial que es resultado de muchas mentes en desacuerdo que eventualmente conviven y ceden pero que rara vez coinciden.

Tal y como dice Lilian Salazar en su artículo no hay una división entre agentes y actores ya que en ciertos momentos ambos son lo uno y lo otro sin embargo por cuestiones de orden separo el escenario, los agentes y los actores en tres diferentes secciones de este documento con la conciencia de que estos elementos no se pueden disgregar para su estudio ya que son parte de un concepto o idea totalizadora que conforma al barrio, al territorio y finalmente a la ciudad. Siendo los «agentes» los que generan en primera instancia el cambio y los «actores» los que lo viven y que son los que generan la producción del espacio social y determinan su vida o su muerte.

Este trabajo comprende los últimos diez años en la vida de estos barrios y el papel que en ella han jugado estos agentes y actores de lo urbano y el papel que ejerce, el hecho de 
que sea un territorio cool, este anglicismo tan popular desde hace aproximadamente cuatro décadas, utilizado para calificar y significar muchas cosas que trato de aclarar en párrafos subsecuentes.

\section{Lo cool}

Este término del idioma inglés que proviene del holandés y que se traduce al castellano principalmente como «fresco», refiriéndose fundamentalmente a la temperatura de algo, en su expresión popular no podía estar más lejos este significado de diccionario, inclusive se usa muchas veces cuando algo esta de moda o «caliente».

Este término popular del argot de los Estados Unidos tiene la característica de que se adopta en muchos países en su forma original y con significados muy similares. El término cool que en México es chido o padre, guay en España, chévere en casi todo Sudamérica o bacán en Colombia ha tenido la capacidad no solo de mantenerse y ser popular durante este tiempo sino que se oye bien sin importar la edad del que lo expresa y no pertenece a ningún estrato social en particular. Es un término vigente a más de cuarenta años de su creación.

Para darle crédito al idioma original a continuación menciono en inglés, solo para fines ilustrativos, una serie de términos que significan básicamente lo mismo que guay y que se utilizan en las mismas circunstancias: socially acceptable, alright, not mean, interesting, sound, awesome, tight, hot, trendy, sweet, great, amazing, rad, nice, calm, wicked, good, chic, bip, fun, neat, dope, crasy, excellent, funny, phat, fresh, pimp, chill, groovy, fantastic, radical, gnarly, super, wow, kool, smooth, spiffy, lame, fine, swell, popular, suave, pleasing, sexy, deserves respect, things that are a fad, liked, in style, where you want to belong, how you want to be, interesting, relaxed, never goes out of style, etc. 
La construcción de lo guay en lo urbano.

Tratando de hacer este mismo ejercicio en castellano podemos decir que cool es: sensacional, padre, lo de hoy, chido, fashion, rico, la neta, chic, de moda, caliente, con estilo, guay, fregón, agradable, súper, wow, estupendo, simpático, interesante, excelente, merece respeto, donde se quiere pertenecer, como se quiere ser, fantástico, a gusto, calmado, al que hay que seguir, al que hay que imitar, a donde hay que ir, atractivo, pertenece, con sabor, con ambiente, interesante, pies plantados en el piso, fresco, tranquilo, relajado, divertido, aventura, buen gusto, confort, simpático y es una forma de actuar, de sentirse, de verse y de oírse, etc.

Lo cool o guay, hasta donde me ha sido posible investigar, no ha sido motivo de múltiples tratados y estudios sin embargo su aplicación en la moda, en la mercadotecnia, en lo urbano referido a la vestimenta de los jóvenes y en el lenguaje coloquial la convierten en un elemento calificador de un fenómeno que en nuestro caso se aplica a la revitalización urbana. Un fenómeno que genera en el espacio urbano una vitalidad con un gran poder de convocatoria y un deseo generalizado en algunos sectores de la población, de estar, utilizar e identificarse y tener un sentido de pertenencia en estos espacios.

Este término surge en los años sesenta del siglo pasado como una expresión del movimiento anti-establishment americano en el que lo cool es todo lo que va en contra de lo establecido. Cool son las comunas, el pelo largo, los hippies, la marihuana, el Volkswagen Beetle, las camionetas VW Combi, las flores, la paz y el amor, el rock, las doctrinas y religiones asiáticas, etc.

En los años posteriores a la Segunda Guerra Mundial, la estabilidad produce en la sociedad de Estados Unidos una especie de sopor que provoca un estado aparente de estancamiento social en el que la forma de vivir se uniforma y se mecaniza. La sociedad vive en una rutina aburrida y poco creativa en la que se limita a trabajar y a vivir bajo un modelo plástico de lo que de- 
bería ser la vida ideal de la clase media americana. Todos aspiran a tener las mismas casas, vivir en los mismos suburbios, vestirse igual y tener familias similares (Frank, 1997: 10). El que se salía de estos patrones era criticado y estigmatizado. En lo urbano se presenta un auge en la intención de promover la «utopía suburbana» y continúa por lo tanto la tendencia de terciarización de los centros históricos de las ciudades americanas.

Es probablemente una respuesta contra la conformidad la que dispara este movimiento ya que se presentaba una marcada intolerancia contra cualquier actitud que se apartara del consentimiento general. Inclusive hay autores que la llaman la «era del consenso» y este movimiento produce precisamente la reacción contraria, una reacción que desbalancea a las generaciones y produce cambios profundos en la forma de ver la vida. Probablemente uno de los aspectos y logros más importantes de este movimiento es que con el solo hecho de existir «rompe la rutina» que imperaba en la sociedad americana en general.

El que probablemente expresa en forma más clara este concepto es el autor Norman Mailer quien en una entrevista dice lo siguiente: «Tenemos que arrancarnos de la seguridad física y espiritual, vivir para disfrutar de inmediato y no posponer el gozo, divorciarse de la sociedad, existir sin raíces, ir a un viaje sin mapa». Lo que aquí expresa Mailer es la antítesis del hombre vestido de traje gris (Frank, 1997: 12).

Este movimiento social de los jóvenes ofrece autenticidad, individualidad, diferencia y rebelión y curiosamente lo hace en un ambiente de jovialidad. El establishment mercadotécnico ve en este movimiento una oportunidad de promover productos con elementos con los que los jóvenes se identifican y es así como se anuncian automóviles con el símbolo de «paz y amor», flores en las cajetillas de cigarros, fabricantes de automóviles que venden lo hip y lo cool, etc. Empieza a tener más peso el diseño, lo que se ve y lo que se siente de las cosas y de los lugares. 
La construcción de lo guay en lo urbano.

Este afán de distinguirse y de ser diferente es el que provoca una mayor sensibilidad a lo estético y a lo bello. Toman estos dos conceptos como una forma de vida y se vuelven más sensibles al potencial y al resultado estético de los objetos y al de la vida en general. En esta primera época de lo cool el que se hace viejo, sobretodo en sus actitudes, deja de serlo y se transforma en uncool, en España se podría expresar como fatal o desastroso.

Esta «contracultura» que produce en la sociedad un profundo miedo a sus jóvenes celebra lo subjetivo, lo espontáneo, lo diferente y las formas de reconocimiento individual. Revoluciona la forma de vivir, aprecia el tiempo libre y el ocio y lo que es más importante; genera una nueva sensibilidad cultural. Cambia la ropa, el peinado, la música, el cine, la mercadotecnia, las novelas, etc., y se ven influenciadas todas las expresiones culturales. Mucho de esta forma de ver la vida persiste hasta nuestros días y se refleja en la selección del lugar donde desean vivir los jóvenes y un número importante de miembros de otros grupos de edad.

Las agencias publicitarias de esta época estaban también estancadas en este mar de conformismo y algunos de sus creativos ven en este movimiento una oportunidad de salirse de los patrones establecidos por esta sociedad del «no cambio». Se empieza a dar libertad a los creativos quienes ven un nicho de oportunidad en todos estos símbolos de la «contracultura» para su utilización para venderle a los jóvenes. Empiezan entonces a aparecer signos de «paz y amor» en anuncios de automóviles o de cigarrillos y en las ventanas de Starbucks en Seattle a principios de los 70, flores en comerciales de restaurantes y en las etiquetas de refrescos y bebidas de todos tipos, etc.

A las agencias publicitarias les gusta el movimiento de la contracultura y la aprovechan para crear ofertas mercadotécnicas diferentes a las existentes. Asimismo le venden y le dan la oportunidad a la gran mayoría de personas de ser «bohemios» 
de tiempo parcial. Lo bohemio es menos estructurado y más natural y permite una existencia más espontánea con una dosis de aventura y de lo imprevisto. Ponen el los labios de todos la palabra cool. El hablar en estos términos le permitía al que los usaba dar la imagen y tener la posibilidad de sentirse temporalmente alternativo y radical.

Esta nueva cultura adopta al arte y a lo bello casi como una forma de vida y el diseño se empieza a convertir en un aspecto importante de la vida cotidiana. Se empieza a generar una actitud de promover la creatividad con sus dosis de intuición, de lo no racional, de lo excéntrico y de lo muchas veces impráctico (Frank, 1997: 42).

La publicidad convierte cool en un término familiar que ya no es propiedad exclusiva de la juventud de los años sesenta y setenta sino actualmente lo utilizan personas de cualquier edad y prácticamente de cualquier estrato social y que curiosamente se sigue usando con la virtud de que nunca se oye mal.

Lo guay como concepto es también algo que califica la forma en la que alguien se ve y actúa, es por lo tanto también una actitud. Hay quien se va al extremo de decir, aunque lo hace en un tono un poco sarcástico, que «para triunfar en la vida es más importante verse cool, sentirse cool y actuar cool que haber ido a la universidad» (Grossman, 2003: 2). Es una actitud que crea tendencias, lo cool o guay es pues un concepto, una idea totalizadora.

\section{Lo guay y la revitalización privada de la ciudad}

Tal y como menciono en el capítulo anterior esta cultura de los años sesenta y setenta del siglo xx provoca que la gente se vuelva sensible al arte, a lo bello y al diseño y adquiere un aprecio por lo diferente, lo radical y lo alternativo que persiste hasta nuestros días. 
La construcción de lo guay en lo urbano.

El diseño es otro punto medular en esta nueva corriente cultural que ha adquirido cada vez mas, una mayor relevancia en la percepción de la gente y en lo que quieren o no quieren adquirir o disfrutar. Tal y como lo define Sir Ernest Hall del British Design Council: «El diseño es una forma de demostrar lo hermosa que puede ser una cosa, es una forma de cambiar la vida y de influir en el futuro» (Peters, 2005: 26).

El diseño se convierte en un generador de valor, es como dice Steve Jobs $^{2}$ el espíritu de una creación. Un buen diseño se vuelve un generador de una atracción profunda y de una conexión emotiva con el objeto. En el caso de la ciudad este buen diseño genera un ambiente, que genera una experiencia.

«Las ciudades son siempre cosas produciéndose, aconteciendo o sea son K, la potencialidad» (Calasso, 2002: 42). Esto pasa en la ciudad con estos antiguos espacios privilegiados que han ido a menos y que tienen la posibilidad de revaluarse como en el caso de las Condesas gracias a actores con la sensibilidad de detectar el potencial de reciclaje, revitalización y de renovación en esta «centralidad descentrada». Este potencial es el que capta el creativo.

El diseño es un ingrediente fundamental de lo cool en la ciudad, es lo que lo diferencia del resto y es lo que le permite revaluarse. Es lo que le permite crear ambientes que llenan las expectativas del que usa la ciudad, es una ciudad con una capacidad altísima de asumir lo actual lo cual le permite resignificarse. Los espacios centrales de la ciudad cumplen muchas de estas expectativas pues tienen elementos que facilitan la integración, son capaces de reciclarse y adaptarse a nuevas actividades y en muchos casos, como en el nuestro, son sustentados por un territorio urbano de mucha calidad.

2 Presidente de Apple Computer, creadores de la computadora Macintosh, del iPod, etc. 
Podemos decir que es un lugar donde se intersectan la forma, la función y la estructura y se produce una revaloración del territorio. Un territorio donde circula la «clase creativa» y la que quiere ser. Es un territorio que produce una conexión emotiva que genera una impresión de exclusividad siendo que permite que todos puedan estar ahí. Así como el paisaje es «un lugar interpretado» ${ }^{3}$, estos barrios son reinterpretados por los actores que interactúan en estos espacios quienes son lo que le asignan o le retiran el estatus de un lugar de moda o guay.

Todo esto sucede en un espacio urbano hecho en otro tiempo para otra cosa pero aunque el espacio se queda estático la sociedad le va encimando sus necesidades y forzando sus expectativas. Es en estos espacios donde podemos captar la realidad de la sociedad en lo urbano ${ }^{4}$.

Es importante mencionar que hay un programa en el estado de Michigan en Estados Unidos llamado «Cool Cities», iniciado a mediados de 2003, cuyo objetivo es «proporcionar fondos para crear ciudades que a base de planeación y programas de reconversión se conviertan en polos de atracción de gente creativa y sirvan de imán para actividades productivas». Asimismo pretenden provocar un ambiente adecuado para atraer talento, promover la innovación y alentar la diversidad. Si nos detenemos a analizar estos conceptos veremos que son congruentes con lo expresado en el capítulo anterior y que se refiere con la generación de un concepto total de ciudad. Este programa quiere promover lugares lo suficientemente agradables en todos sentidos donde la gente quiera vivir. En este punto se genera una cuestión que es si se logrará este resultado forzando artificialmente el efecto de lo guay en estas revitalizaciones patrocinadas por un gobierno estatal.

\footnotetext{
3 Dr. Juan Luis de las Ribas, clase de doctorado Universidad de Valladolid, abril 2006.

4 Dr. Mario Camacho Cardona, clase de doctorado Universidad Iberoamericana Puebla, marzo 2006.
} 
En el caso que nos ocupa esta revitalización se ha hecho paso a paso y sin intervención del gobierno. Debido al carácter multifactorial de las revitalizaciones urbanas, no podemos decir que el gobierno no ha tenido un papel en este fenómeno de estos barrios de la ciudad de México, pero más bien en forma indirecta como podremos ver en capítulos subsecuentes.

\section{La «operación hormiga»}

En las Condesas este fenómeno ha sido producido por una especie de «operación hormiga» o sea poco a poco, con capital privado y durante un largo periodo de tiempo. Aunque el proceso acelerado y el auge de esta revitalización se ha dado en los últimos diez años (1996-2006) este es producto de acciones micro de agentes y actores urbanos que con su capital han intervenido en forma individual y puntual en este territorio urbano durante varios años.

Probablemente son los despachos de creativos los que inician este fenómeno desde los años setenta y ochenta del siglo pasado al ocupar los huecos dejados por la gran cantidad de familias que se van a vivir a los nuevos fraccionamientos de las periferias de la ciudad de México. En los noventas son los restauranteros, los arquitectos como promotores con intervenciones importantes (por su efecto pero no por su escala) pero aisladas y jóvenes que rentan o compran en un territorio donde los precios eran todavía accesibles gracias al terremoto de 1985 y gracias a una emigración continúa hacia las periferias. Los diseñadores de modas, diseñadores de muebles, publicistas, cineastas, diseñadores, arquitectos, escritores, músicos, etc., han hecho de las Condesas no solo su lugar de trabajo sino que en muchos casos también el de su residencia. Una tendencia cada vez mayor de trabajar como freelance de estos creativos y el avance en las comunicaciones ha motivado que se dé con más frecuencia la combinación casa-oficina. 
Posteriormente es el turismo y los visitantes locales los que ponen a este territorio en las candilejas de lo urbano y lo clasifican como el lugar «donde hay que estan». Esta actitud implica también una estrecha relación entre lo guay y el estilo de vida, un querer vivir lo que se es (para el pequeño grupo que reúne las condiciones que dicta un sector de lo que es cool) y para el resto de los humanos que son muchos y que aunque no serían clasificados como cool, definitivamente muchos querrían serlo.

«En la ciudad divertida, la competencia real no gira ya en torno a la cuota económica de mercado. Estamos compitiendo por la atención, por la cuota de mente y por la cuota de corazón» (Peters, 2005: 139).

Esta «operación hormiga» construida en el tiempo con participación individual adquiere una fuerza que no tienen las grandes revitalizaciones planeadas y orquestadas por los gobiernos y por el capital privado. Esta se construye a base de esfuerzo individual y pequeño capital en la que se dan situaciones de cohesión social y de alianzas que en otras circunstancias serían improbables. El notario, el contador que tiene su oficina en la cuadra, el motociclista vestido en piel negra de Harley Davidson, el estudiante universitario, el «Darketo» y la señora judía de setenta años de edad que forman una alianza para luchar contra el que quiere vender droga en la esquina, contra el que usa las banquetas de las casas como estacionamiento de su restaurante o contra el desarrollador que pretende demoler una casa catalogada art déco. Este tipo de alianzas que en otras condiciones calificaríamos como «imposibles» se dan en estos barrios en forma cotidiana y con la ventaja de que fortalecen la cohesión social y reafirman la identidad.

\section{Lo «uncool»}

Definitivamente lo contrario de lo que quisiéramos que fuera la ciudad donde vivimos se produce también como efecto 
La construcción de lo guay en lo urbano.

contrario y paralelo de lo cool. Dentro de este fenómeno se dan pugnas entre lo comercial contra lo habitacional, lo tradicional contra lo «alternativo», lo popular contra la elitización, la gentrificación del barrio, etc. Todos tratando de predominar pero al mismo tiempo y en forma paralela luchando contra amenazas comunes.

Los residentes originales se sienten invadidos y los residentes nuevos se sienten amenazados por los más nuevos. Lo cool genera un sentimiento de identidad, sobretodo en los recién llegados, que en muchas ocasiones minimiza y hace tolerable las muchas molestias que se generan como un daño colateral de la revitalización. Ante la «distinción» que genera el vivir en una zona cool se crea probablemente una barrera de humo contra lo negativo que hace más tolerable y llevadera la vida en estos barrios.

Más gente significa más actividades, más movimiento es más tráfico ${ }^{5}$, más delincuencia ${ }^{6}$, más actividad comercial y turística y consecuentemente una mayor derrama económica. Estos factores hacen que los delincuentes pongan su atención en esta zona desgraciadamente antes de que las autoridades hagan algo por evitarlo. La proliferación de bares, restaurantes y discotecas han traído a esta colonias; ruido, venta de droga y prostitución.

La falta de estacionamiento ha provocado veintenas de servicios de «valet parking» que básicamente cobran por llevar a estacionar el automóvil a tres o cuatro cuadras sin ningún tipo de seguridad y muchas veces frente a la puerta de la casa de un residente molesto. Este mismo problema ha generado también una nueva actividad urbana que es la del «franelero» ${ }^{7}$ quien se

5 Se calcula que circulan a través de las Condesas más de 100000 vehículos diariamente.

6 Se roban tres automóviles en promedio diariamente en estos barrios más múltiples robos de autopartes.

7 Traen en la mano para señalar un trapo o franela y apartan lugares en la calle por los que cobran una cuota. 
apropia de un tramo de vía pública, aparta espacios y cobra por su uso como si fuera un estacionamiento privado. Hay una mayor contaminación, se han devastado algunas de sus áreas verdes y los residentes se siente invadidos.

A casi once años del Bando $2^{8}$ ha habido múltiples reacciones a la densificación que esta disposición promueve. Esta densificación parece no agradar a la ciudadanía, según un artículo de Luis Zamorano para la Fundación Metrópoli 2205, en el que comenta como principales razones de este rechazo a la falta de capacidad de las infraestructuras y de los servicios públicos para poder alojar y dar servicios adecuados a un número mayor de usuarios. Los dos renglones de estos servicios que la ciudad siente menos capaces de resistir este aumento en la densidad son; el abastecimiento de agua potable y las vialidades (Zamorano, 2006: 1).

Este rechazo ha sido lo suficientemente fuerte para replantear y modificar los programas de densificación de varias de las alcaldías centrales tales como Álvaro Obregón, Coyoacán y Miguel Hidalgo y reducir las densidades programadas en la alcaldía Benito Juárez. Se calcula que para fines de 2006 las viviendas nuevas construidas en estas delegaciones desde la promulgación del bando antes mencionado ya era de 60 mil que representan aproximadamente 240 mil nuevos habitantes, estas cifras se han multiplicado prácticamente en forma aritmética desde esa fecha.

Un gran porcentaje de los vecinos de las delegaciones incluidas en el Bando 2 consideran que «a mayor número de habitantes en sus colonias mayor es el deterioro en la calidad de los servicios» (Zamorano 2006: 4). Esta percepción se basa en que han sufrido de escasez de agua potable, problemas viales importantes, falta de estacionamiento y en algunas colonias apagones más

8 El Bando 2 es un reglamento elevado a ley creado por el Gobernador de la Ciudad de México fundamentalmente para redensificar las cuatro delegaciones centrales de la ciudad. 
frecuentes. Es una realidad que la infraestructura de los servicios públicos de la ciudad de México es antigua, no tiene un mantenimiento adecuado y no es de muy buena calidad lo que provoca que la demanda adicional no sea adecuadamente cubierta.

\section{La primera Condesa}

La Colonia Condesa se funda iniciando el siglo xx y para ser preciso en el año 1902, posteriormente se construye dentro de ella la plaza de toros de la Condesa y el hipódromo que es inaugurado en 1910 en el arranque de la Revolución Mexicana. Al terminar la revolución se inicia un proceso de inmigración proveniente de todos los rincones del territorio nacional que llegan a la capital en busca de mejores oportunidades. Este movimiento poblacional genera un crecimiento muy rápido del área urbana. Un crecimiento que se da fundamentalmente por la generación de rentas y no porque la población así lo requiriera.

Mientras esto sucede el centro histórico empieza a sufrir un cambio de uso e inicia una tendencia muy clara hacia a la terciarización con actividades comerciales y de servicios, se empiezan a construir grandes edificios y se revalúa su suelo contrastando con los valores de la nueva oferta inmobiliaria. Esto obliga a que los habitantes tradicionales del centro histórico comiencen a trasladarse a estos nuevos desarrollos que les brindan una posibilidad de adquirir una vivienda. Las Condesas tienen este perfil, sus promotores implementan esquemas de crédito que permiten a una recién creada y creciente clase media comprar una vivienda y constituir un patrimonio.

Estos barrios han alojado desde su creación al Jockey Club, al Hipódromo de la Condesa, el Club Hípico Alemán, la plaza El Toreo, una de las primeras tiendas departamentales que salieron del centro histórico (el Palacio de Hierro), el primer supermercado y muchos otros edificios notables de la ciudad de 
México. Otro de los aspectos muy importantes de este territorio es que alojó a las que son probablemente las inmigraciones más importantes y significativas que ha tenido este país desde la colonia; en 1922 un grupo importante de judíos europeos y en los años cuarenta son los españoles, en su mayoría refugiados de la Guerra Civil que habían llegado en 1939, quienes escogen la Condesa para hacer de ella su hogar en México. Un número muy importante de miembros de ambos grupos se asientan en este territorio urbano y lo transforman con sus panaderías, colegios, centros culturales, sinagogas, carnicerías y tiendas de abarrotes y en forma más importante con sus tradiciones y cultura. (Porras, 2001: 142).

\section{El escenario}

Parafraseando el dicho de los inmobiliarios que dicen que lo único que importa en el éxito de una promoción es la ubicación, podemos afirmar que en este sentido las Condesas cumplen con todas las características de lo que podía ser una «magnifica localización». Aquí se puede aplicar también el título del libro de William Hudnut Halfway to Everywhere («A medio camino de todos lados»), en el cual se analizan los primeros suburbios ahora anexos a los centros de las ciudades americanas. Esta percepción de estar «a medio camino de todos lados» se cumple cabalmente en las Condesas. Están rodeadas de vías, que en algún momento de la historia fueron rápidas o semirrápidas, y que prácticamente comunican a las Condesas en cualquier dirección. Es lugar de paso que a diferencia de otros no se percibe como transparente o invisible sino que cautiva y en cierta forma cobija.

Es su posición central la que la hace que se ubique virtualmente equidistante de «lo demás» de esta megaurbe en las que las distancias no se miden en kilómetros sino en horas de recorrido. Es central sin la carga emocional que implica el solo 
pensar en atravesar o recorrer el centro histórico con su estigma de complicación vial producida por el tráfico y las recurrentes marchas de manifestantes de todas las especialidades posibles.

Los tres barrios y en especial la colonia Hipódromo cuentan con una infraestructura viaria y de equipamiento que fue motivo de estudio urbanísticos y protagonista de publicaciones desde su creación. El que ahora cuente con parques y magníficos camellones en sus avenidas y bulevares tiene en parte su origen en un convenio por el cual los terrenos del antiguo Hipódromo de la Condesa, que fue cerrado en 1914 a solo cuatro años de haberse inaugurado, al ser vendidos por el Jockey Club no se podrían urbanizar hasta transcurridos quince años después de la operación de compraventa.

El arquitecto José Luis Cuevas, quien ya había diseñado cuatro años antes el fraccionamiento Lomas de Chapultepec es contratado para su diseño y logra desarrollar un concepto no ortogonal basado en la idea del trazo del óvalo de la antigua pista de carreras del hipódromo. Lo anterior aunado a lo espléndido de la dotación de plazas, glorietas, camellones y áreas verdes y al planeamiento de un fraccionamiento moderno con servicios y equipamientos tales como: teatro al aire libre, estación de gasolina, hospitales, cines, iglesias, escuelas, etc. Este fraccionamiento le sirvió de ejemplo al ayuntamiento para fijar los parámetros de nuevos desarrollos de características similares.

Se ofrecía el buen gusto y el confort así una nueva forma de vivir, que probablemente catalogaríamos como cool en nuestros días, gracias a la calidad sin precedentes en el país del equipamiento urbano con parques como el México (solo superado en extensión por la Alameda central y el parque de Chapultepec), glorietas, plazas y amplias calles y avenidas. Se promovía para su venta en 1926 como la zona que sería en poco tiempo el «corazón del México moderno». 
La variedad y riqueza de su arquitectura es otro de sus mayores atractivos. Ahí encontramos representados el estilo porfiriano con una franca influencia francesa; el neocolonial basado en el barroco mexicano; el que se denominó californiano que es una mezcla de colonial mexicano con lo que en ese entonces se estilaba en el estado de California en Estados Unidos; edificios racionalistas o funcionalistas que producen los arquitectos mexicanos por los planteamientos y propuestas de Le Corbusier mismas que en México conforman el movimiento denominado racionalismo mexicano y finalmente y en forma muy importante el estilo por el cual las Condesas son más conocidas; el art déco.

En los años sesenta y setenta se construyen una cantidad importante de edificios de departamentos en régimen en condominio, de estilo indefinido, muchos de los cuales sufrieron daños en el temblor que sacudió a la ciudad de México en el año de 1985.

La arquitectura vuelve a ser ahora uno de los protagonistas más importantes en este territorio urbano ya que gracias a varios jóvenes arquitectos y a otros no tan jóvenes pero muy conocidos, $y$ en forma más importante gracias a Javier Sánchez y a su despacho Higuera + Sánchez quien inicia en 1996 este movimiento (con la construcción de un edificio de 4 departamentos en la calle de Veracruz esquina con Cuernavaca), es ahora la arquitectura una de las razones más poderosas para vivir o visitar las Condesas. La calidad del diseño de estas nuevas construcciones las ha puesto en las guías de los mochileros y entre otras en las de los estudiantes y amantes de la arquitectura.

Se esperaría que este auge de creación de nuevas construcciones no tuviera fin debido a su gran éxito sin embargo el alto costo de la tierra ahora sobre valuada, la gran cantidad de edificios en condominio con dos o tres décadas de construidos que podrían ser sujetos de remodelación pero que por la pulverización de la propiedad resultan prácticamente imposibles de renovar y 
finalmente la recién adquirida cohesión social de los habitantes de estas colonias que están demandando cada vez más, restricciones más exigentes para evitar las innumerables molestias que este cambio en la vida de la colonia ha provocado que los agentes inmobiliarios dirijan su atención hacia otras colonias cercanas.

Aceras anchas capaces de alojar mesitas de bares y restaurantes, camellones anchos arbolados que dan sombra y frescura al peatón y visualmente al que circula en algún vehículo, comercios vitales mezclados con boutiques y restaurantes de comida de fusión, el mercado barrial y galerías de arte, la ciudad donde se puede caminar y tener intercambios personales en la esquina, son algunos de los ingredientes que hacen de este territorio la «ciudad simpática» como la llama Fernando Roch y que ejerce una atracción en el ciudadano que descubre esta «ciudad» dentro de la «otra», la que ya no se sabe que es. El escenario es pues un lugar producto de prácticas culturales anteriores en diálogo con las actuales que se asienta sobre un espacio capaz de adaptarse y moldearse a estas nuevas demandas sociales.

\section{Los agentes}

A partir de finales de los años sesenta y principios de los setenta las Condesas empiezan a sufrir un fenómeno que comparten con otras zonas centrales de la ciudad; la producción de ciudad por agentes inmobiliarios a base de nuevos espacios periféricos provoca una emigración lenta pero constante hacia las periferias. Se empieza a dar un movimiento constante de población hacia nuevos fraccionamientos en las periferias de la ciudad. Otra emigración importante se produce a raíz del sismo de 1985 que daño un número importante de edificios de departamentos, fundamentalmente los de construcción reciente y que permanecieron durante mucho tiempo deshabitados e incluso algunos se demolieron. 
Dado que la producción de ciudad es una tarea de lo social, esta emigración empieza lo que podemos llamar un periodo lento pero consistente de declive en la calidad de las Condesas. La ciudad de México crece en grandes proporciones y esto permite que esta zona, por su ubicación y extensión, cambie de usos con una tendencia hacia la actividad terciaria pero todavía con un predominio muy importante de lo habitacional.

Dentro de esta terciarización del territorio y de esta puesta en escena social, son los restauranteros quienes empiezan a generar «ruido» sobre los atractivos y virtudes de estas colonias. Con pocas intervenciones pero muy puntuales, en el año 1993 dos o tres nuevos restaurantes se suman y conviven con los que siempre habían estado ahí, son la punta de lanza de un gran movimiento que a la fecha ha generado la apertura de más de cien negocios de comida con todo tipo de menús y precios y clientela de todos tipos y niveles. Otra rareza en el espacio urbano de la ciudad de México en ese momento era el de tener mesas en la acera. Se vuelve el comercio un vínculo social entre lo público y lo privado. Lo público como materialización de lo compartido. El comercio asegura la presencia de lo privado y el espacio público y lo público en el espacio privado.

Por su encanto y diversidad estos barrios se constituyen en una nueva oferta para el «nuevo cliente mexicano» joven e informal, que ha viajado, tomado vino y ha comido en aceras en Europa y Estados Unidos. Un joven de aproximadamente veinte a treinta y cinco años de edad que vive solo, comparte con algún amigo los gastos o vive con su pareja quien a su vez también tiene un ingreso. «Treinta años que ya son treinta y cinco» según la teoría de Lev Grossman de Time Magazine quien afirma que las edades se han ido recorriendo y que por lo tanto el llamado «joven contemporáneo» que viaja mucho, que no tiene hijos y que cuenta con un buen nivel de ingresos importantes va a buscar vivir en estas zonas cool de la ciudad. 
La construcción de lo guay en lo urbano.

En este mismo rango de edad están las mujeres que buscan este tipo de espacio urbano por lo práctico y conveniente y por la seguridad que da el movimiento de tantos extraños (Jacobs, 1961: 21). Cada vez más mujeres jóvenes están viviendo solas y muestran una marcada preferencia por esta colonias de la centralidad. Esta preferencia de residencia tiene la ventaja, para estos barrios, de que las mujeres son más comprometidas y participan y se involucran más que los hombres en las organizaciones civiles de vecinos de todos tipos?.

El promotor turístico descubre hace poco que había viajeros que ya habían «descubierto» las Condesas. Se promueve como un atractivo más de la ciudad de México fundamentalmente dirigido al viajero joven y al sector turístico que busca y le interesa la arquitectura, el arte y la cultura. Hay varios hoteles en la zona como el recién inaugurado Hotel Condesa D. F., en el cual los protagonistas son la arquitectura minimalista y artistas y bohemios con dinero que aprecian el «glamour» de este sector de la ciudad de México que se ha constituido como un distrito recreativo cuyo principal atractivo es que sigue siendo ciudad.

Los despachos de creativos son un punto medular en cuanto a la conformación actual de estas colonias. Hace ya dos o tres décadas que estos despachos descubrieron que muy buenas casas, que habían sido dejadas por familias que en muchos casos se habían mudado a fraccionamientos de la periferia, se rentaban y se vendían a precios muy razonables y no tenían problema en cuanto a la obtención del uso del suelo para oficina y uso comercial.

Este sector, probablemente más sensible a su contexto que otros, captó el atractivo y el «sabor» de la zona y se corrió la voz en los diferentes gremios relacionados que han hecho de estos

9 Según entrevistas en vídeo realizadas por estudiantes de Sociología del Campus Azcapotzalco de la Universidad Autónoma Metropolitana, dirigidas por la Mta. Concepción Huarte. 
barrios su hogar profesional y en muchos casos su hogar «hogar». Los creativos, que en muchos de los casos realizan trabajo independiente, han combinado su lugar de trabajo y de habitación en un mismo espacio, con la ventaja adicional de estar en un territorio bien ubicado, divertido, acogedor y lleno de servicios.

Es por esto que hay una importante población de arquitectos, diseñadores gráficos e industriales, diseñadores de modas (que aprovechar tener comercios a la calle), publicistas, editoriales, fotógrafos, productoras y agencias de cine, pintores, periodistas, escritores, agencias de modelos y actores, etc., que cuando asumen su también papel de actores le dan al barrio, como dice el antiguo refrán mexicano, «más sabor al caldo».

Las Condesas tienen también una amplia tradición como un territorio que aloja y protege al arte y la literatura con sus creadores dentro de su territorio. Esta vocación ha generado que las galerías y estudios de arte sean también parte medular de la vida de esta perfectamente delimitada sección del tejido urbano de la ciudad.

Aunque los despachos de creativos, los restauranteros y muchos jóvenes sin posibilidad de comprar o rentar casas y departamentos en otras colonias por su costo, ya habían dirigido su atención hacia estos barrios de la ciudad, es con el inicio del siglo XXI que se dan algunas coincidencias y algunas buenas decisiones que provocan que se destape este desarrollo. Entre otras puedo mencionar la decisión del empresario Carlos Slim de invertir en el centro histórico de la ciudad, el lanzamiento del Bando 2 del Jefe de Gobierno de la ciudad y el hecho de que por razones que más adelante analizaremos se convierte en una de las zonas más dinámicas y de actualidad de la ciudad.

El centro histórico había perdido el $40 \%$ de la población que tenía en los años setenta; un grave deterioro de sus inmuebles motivado por su abandono y por su antigüedad con la casi nula 
inversión en conservación por parte de sus propietarios; había sufrido la degradación de sus espacios públicos y una drástica terciarización en sus actividades que había repercutido en la ya de por sí dramática pérdida de oferta de vivienda en arrendamiento. Todo lo anterior sumado a la sustitución de las viviendas por comercios, bodegas y oficinas, la falta de seguridad y los efectos devastadores del sismo de 1985.

Entre las acciones que han emprendido están una campaña mediática muy importante para concienciar a la población sobre la importancia de la centralidad y el papel que juega en la ciudad; se han emprendido obras con una estrategia que ha logrado restaurar y redignificar varias secciones del centro y al mismo tiempo desplazar a los vendedores ambulantes y evitar que se vuelvan a instalar. La difusión de esta acciones y el volver a poner a la ciudad histórica como una opción viable de residencia han hecho que colonias como las Condesas se beneficien indirectamente de todas estos programas de revitalización urbana.

El Gobernador de la Ciudad de México, preocupado por la subutilización de la infraestructura urbana del Distrito Federal lanza en diciembre de 2001 el denominado «Bando 2» se promueve la redensificación habitacional en las cuatro delegaciones centrales que son: Cuauhtémoc (que es donde se ubican los barrios motivo de este estudio y también el centro histórico de la ciudad), Benito Juárez, Miguel Hidalgo y Venustiano Carranza. En este documento se aprecia la preocupación del hecho que estas delegaciones centrales han perdido población (se menciona un descenso de 1200000 de habitantes en los últimos treinta años) mientras que las delegaciones del sur y del oriente de la ciudad han crecido en forma desproporcionada. Esta resolución permite la construcción con una mayor densidad, con apoyos especiales a los promotores y mayor facilidad en la obtención de los permisos de construcción. 


\section{Los actores}

Son estos con sus vivencias quienes construyen y se apropian el espacio social, son los que sienten, sufren y disfrutan el espacio urbano. Son los que convierten un lugar en mágico y lo ponen de moda, lo vuelven cool o lo desaparecen del imaginario urbano en un momento. Gente que juega un papel determinado y que quiere que la vean y ser vista y otras que quieren ver pero no ser vistas, todas ellas parte del «paisaje humano» de la ciudad.

Estos barrios han sido desde su creación residencia de artistas e intelectuales famosos, presidentes de México, la comunidad judía y la española, intelectuales expatriados y los primeros integrantes de la clase media mexicana han dejado huella de su historia en las Condesas. Estas colonias tiene impresas en sus espacios vivencias de mucha gente notable en la vida de este país $\mathrm{y}$ de otros no tan notables pero igualmente importantes.

Después del sismo de 1985 por el cual muchas familias salieron de esta zona se abre un espacio para jóvenes y familias de clase media que son atraídos por lo atractivo de esta zona y que deciden hacer de las Condesas su residencia. Estos recién llegados se mezclan por lo espacioso de los departamentos y precios de compra venta y de rentas bajas, esto permite que siga prevaleciendo lo habitacional sobre el terciario y que la colonia siga teniendo vitalidad, una vitalidad disminuida pero que le permite mantener su interesante vida urbana.

Es a fines de los años noventa cuando son los jóvenes bohemios los que atraídos por la ubicación y su magnífica infraestructura hacen de este espacio una zona de moda, un territorio cool. Esta vida de barrio se ve trastornada con la llegada de yuppies, neohippies, yoguis, algunos junkies, mochileros, arquitectos, grupos de motociclistas, intelectuales, chicas fresas (de la alta sociedad), productores de cine, ejecutivos de negocios, periodistas, intelectuales, artistas, amantes del arte y de la buena 
comida, turistas, solteros y divorciados de cacería y probablemente algunos estudiosos de la vida de la ciudad entre otros muchos personajes que han descubierto y escogido este territorio urbano para desempeñar un papel y observar y ser observados.

Estos son elementos de diversidad de un espacio que ofrece cosas, no es de paso, es de estar. Tribus que sin embargo se mezclan entre ellas en un escenario, que solo puede proveer el espacio público con su neutralidad, sin temor a perder su espacio ganado a pulso por la apropiación pacífica de su presencia cotidiana. Es un lugar donde podemos aplicar con una gran confianza el principio de la igualdad que nos da el derecho a ser diferentes.

Es pues una urbanización sociocultural producida por gente que busca el encanto de la diversidad y las esencias del barrio y que descubre una ciudad dentro de la ciudad muy diferente a la que usualmente percibe. Esta ciudad descubierta que es la que llena huecos en la ilusión de lo urbano del que ya la conoce y del que la empieza a conocer. Esto es parte de lo cool que ejerce una liga con la ciudad imaginada como un lugar donde se es original, único y perteneciente a un grupo supuestamente selecto que puede platicar que vive precisamente ahí.

Las Condesas tienen el encanto de lo global y lo cosmopolita sin la necesidad de prescindir de lo popular y de lo vital. Es notable la cantidad de comercios de barrio que reflejan la todavía predominante vocación habitacional de estos barrios. Hay misceláneas (pequeñas tiendas de abarrotes), tlapalerías (versión pequeña de una ferretería), panaderías, tintorerías y lavanderías, reparadores de zapatos, heladerías, sastres y costureros, carpinteros y tapiceros, carnicerías, pescaderías, mercados, supermercados, etc., todos ellos conviviendo con actividades nuevas como las galerías de arte, los restaurantes de nouvelle cuisine o de comida fusión, las comercios de muebles italianos, centros de meditación y yoga, boutiques de ropa de diseñadores connota- 
dos, tiendas de decoración, etc. La Condesa es ya un centro de expresiones artísticas y de intercambio cultural y ubicación predilecta de talleres de artistas y despachos de creativos.

Estamos apropiándonos de espacios antiguos y los estamos utilizando en formas modernas. Está nueva construcción de lo urbano hace que el territorio se resignifique ya que toda esta actividad adaptativa se materializa en el espacio público y hace de la experiencia urbana algo interesante y divertido y crea en sus habitantes, permanentes y temporales, un sentido de pertenencia y de identificación. Es probablemente por esto que lo lúdico es ahora un sello de esos barrios y un imán para atraer visitantes y consecuentemente una importante actividad comercial.

\section{Conclusión}

Las Condesas conforman un espacio central privilegiado no solo por su ubicación sino por sus características espaciales, un «emplazamiento central sin centralidad» que había perdido su vitalidad. Hace poco más de una década se ha convertido en un lugar de oportunidad debido a que había sido poco valorado pero hubo agentes y actores de lo urbano que captaron su potencial y lo están aprovechando. Agentes y actores en su mayoría jóvenes, de clase media con capital privado limitado pero capaces de captar el potencial de estos barrios, sensibles para detectar la calidad en la infraestructura urbana y con creatividad con sus dosis de intuición, de lo no racional, de lo excéntrico y de los muchas veces impráctico aprovechan esta oportunidad para generar un nuevo concepto de lo urbano, lo que podría ser un tipo de desarrollo urbano emergente.

Lo guay produce una revitalización como en las Condesas que sigue un patrón que no es de libro de texto, sino más bien de pretexto. Es una apropiación de los actores y agentes sin mucho análisis previo más bien con una alta dosis de intuición y de 
aventura. La lógica y el sobre análisis pueden paralizar una idea. La intuición, el deseo de vivir lo cool y la ciudad compacta se vuelven el pretexto para habitarla de los creativos, de los sensibles a este espacio con características especiales.

El sustento territorial del barrio debe de tener potencial, se debe de poder arreglar, mejorar, embellecer, dignificar, etc. Debe de tener calidad o como se dice comúnmente; debe de haber «tela de donde cortar». Esta puede ser el diseño, la concepción del espacio como un todo que sustenta actividades que permiten que se desenvuelva la vida urbana con naturalidad y sin complicaciones. Un lugar que es guay porque celebra lo subjetivo, lo espontáneo, lo bohemio y que está de moda pero es informalmente atractivo.

Lo cool o guay genera una nueva percepción urbana que provoca una conexión emotiva con la ciudad. En las Condesas esto es posible gracias a que sus creadores diseñaron ambientes que generan experiencias que le dan contenido al patrimonio existente y que contrastan con la ciudad moderna con sus espacios especializados generalmente desangelados.

Los que marcan la tendencia son los jóvenes, son ellos quienes determinan si algo es guay, son ellos los que detectan el potencial o siguen a los que lo hicieron, los que marcan las tendencias. Los demás los siguen, en esta era de las comunicaciones es impactante a que velocidad estos lugares guay se promueven y se vuelven famosos.

Es la ciudad con calles que se pueden atravesar, es caminable, con referencias, con esquinas donde hay encuentros y la gente se puede orientar y ejercer su poder de decisión en cuanto a que dirección seguir. Ciudad que permite movilidad exenta de medios mecánicos, que no es imprecisa y que mantiene una escala con la que el ciudadano se siente relacionado. Es una ciudad que te habla, no te grita. 
En las Condesas se permite vivir lo cotidiano pero con un cierto grado de sofisticación. El actor se siente identificado, no siente que se equivocó de escenario, es lo suficientemente complejo y variado que acomoda sin comprometer y permite la adaptación sin forzarla. «Es un lugar donde no se percibe segregación socio espacial y la ciudad nos permite hacer que el pasado sea parte de nuestro futuro al reclamar el espacio urbano. Se da, no sin problemas, la materialización de lo compartido una muestra del arte de vivir juntos como una manifestación de orden social» (Clément, 1985: 21).

Este efecto de lo guay que pone un territorio urbano en escena y que genera una vitalidad que sirve de motor para la revitalización, satisface las expectativas de un grupo o grupos en cuanto a la ciudad imaginada, la que acoge y cobija y que permite su identificación. Se resume en este espacio lo que la gente quiere, las expectativas de otra realidad de ciudad.

Este grupo o grupos que buscan el encanto de la diversidad y las esencias del barrio descubre una ciudad dentro de la ciudad muy diferente a la que usualmente vive y percibe. Esta ciudad descubierta que es la que llena huecos en la ilusión de lo urbano del que ya la conoce y del que la empieza a conocer. Al cumplir estas expectativas del imaginario se vuelven espacios que tienen algo que ofrecer, que satisfacen expectativas de nuestra idea de ciudad.

La zona cool se diferencia de lo demás entre otras cosas por su gran poder de convocatoria. Poder de convocatoria que atrae visitantes, turistas, colonos, negocios, inversiones, cultura, vida, actividad, etc., y en la mayoría de los casos; muchos muchos problemas.

Al entrar en lo guay entra uno al campo simbólico de lo que queremos que sea la ciudad. Es donde hay que estar y se quiere pertenecer. Es probablemente en lo deseado donde lo guay se genera y se contagia a quienes desean pertenecer y participar en 
esta «realidad paralela» que puede llegar a ser engañosa como barrera de humo de lo negativo pero que genera en los que lo usan y lo viven un sentido de pertenencia.

Estas zonas de la ciudad tienen como factor común que son centrales y las sustenta un territorio urbano de mucha calidad. Es donde el entorno urbano ofrece más y es donde se comprueba que la infraestructura de calidad se vuelve la mejor inversión en el tiempo no solo por su atractivo sino por su capacidad de adaptación.

¿Lo guay se puede generar o es un producto social espontáneo o una combinación de los dos? Aunque es innegable el carácter multifactorial de la revitalización urbana considero que lo que ha pasado en las Condesas ha sido en principio espontáneo, no planeado ni dirigido por una persona o un grupo de personas. Ha sido un producto social generado por un grupo, cada quien actuando por su cuenta, que provoca tendencias que otros siguen, difunden y multiplican.

Es un caballo de Troya involuntario, un cambiar desde dentro que hace que dirijan su atención los de afuera, es una suma de esfuerzos individuales que producen un empuje público y una serie interminable de alianzas. El fenómeno se ha producido solo, solo pero ayudado con la capacidad de pequeña inversión privada unida a lo distinto, a la creatividad y a la imaginación. Se da en forma natural, parece un fenómeno exclusivo pero todos pueden estar. Es lo que podríamos llamar una revitalización «hecha a mano», una revitalización compleja no especializada. Esto le da una fortaleza y una cohesión social difícil de lograr en las grandes intervenciones de revitalización montadas y planeadas desde el gobierno o realizadas por los grandes inversionistas privados.

¿Qué papel juega en este proceso el urbanista del siglo XxI? ¿Es el de aprovechar la dinámica y la inercia de este fenómeno para potenciar los beneficios o el de tratar de evitar los daños que esta revitalización produce? 
¿Se puede construir lo guay? ¿Son Chueca en Madrid, Carlton en Melbourne, Le Marais en París, Islington en Londres, Below $14^{\text {th }}$ Street en Manhattan o Gas Town en Vancouver casos análogos a las Condesas o tendrán por lo menos puntos en común?

En su artículo de Time Magazine, Lev Grossman escribe que «lo cool es uno de los recursos naturales más maravillosos: una sustancia invisible e impalpable que puede hacer que algo se vuelva fantásticamente valioso. Y lo que es más importante puede ser usado para predecir el futuro».

Es este factor el que probablemente motiva a los habitantes de la ciudad de México a ser turistas en su propia ciudad y en unos barrios que más que ofrecer atractivos turísticos son un atractivo en sí mismos por su contenido ambiental, su calidad de diseño urbanístico y porque le dan al ciudadano común la posibilidad de sentirse por un rato; sofisticado, alternativo, bohemio e inclusive hasta un poco radical o sea sentirse cool. 


\section{REFERENCIAS BIBLIOGRÁFICAS}

Álvarez Mora, Alfonso (2004). «Modelos de desarrollo urbano. De la ciudad al metropolitano disperso». En Ciudad, Territorio y Patrimonio, materiales de investigación II. México: Universidad Iberoamericana Puebla.

Berridge, Joe (2006). The 21st. Century belongs to cities, artículo de Urban Strategies Inc. Toronto.

Calasso, Roberto (2002). K. Milán: Adelphi.

Carballo, Emmanuel y Martínez, José Luis (1988). Páginas sobre la ciudad de México, 1469-1987. México: Consejo de la Crónica de la Ciudad de México.

Camacho Cardona, Mario (2002). Hacia una teoría del espacio. México: Universidad Iberoamericana Puebla-Benemérita, Universidad Autónoma de Puebla.

Clément, Catherine (1985). Lévi-Strauss ou la structure elle malheur. París: Le Livre de Poche.

Coulomb, René (2005). Recorrido por la Colonia Condesa. Guía: Virginia Rose Priola (VCD), Maestría en Planeación y Políticas Metropolitanas. México D. F.: UAM Azcapotzalco.

De la MazA, Francisco (1974). Del neoclásico al Art-Noveau y primer viaje a Europa. SepSetentas.

De las Ribas, Juan Luis y Vegara, Alfonso (2004). Territorios Inteligentes. Madrid: Fundación Metrópoli.

EILER Rasmussen, Steen (2004). La experiencia de la arquitectura. Barcelona: Reverté.

Espinosa López, Enrique (1991). Compendio cronológico de su desarrollo urbano. Ciudad de México: Banobras.

FERnÁndez, Fernando (1991). «Casas y cosas de la Condesa». Milenio, n. ${ }^{\circ} 6$.

Frank, Thomas (1997). The Conquest of Cool. Chicago: The University of Chicago Press. 
García Bellido, Javier y González Tamariz, Luis (1980). Para comprender la ciudad. Madrid: Editorial Nuestra Cultura.

Grossman, Lev (2003). «The Quest for Cool». Time Magazine, Nueva York.

Hudnut III, William H. (1998). Halfway to Everywhere. Washington DC: The Urban Land Institute.

JACOBS, Jane (1961). The death and life of great American cities. Nueva York: Random House.

Lefebvre, Henri (1973). El derecho a la ciudad. Barcelona: Península.

Calthorpe, Peter y Fulton, William (2000). Designing the region is designing the neighborhood. Nueva York: Routledge.

LiDA, David (s/fecha). «Mexico's City Condesa, The War Between the Trendy and the Traditional», entrevista para Travel Advisory.

Peters, Tom (2005). Essentials. Design. Londres: Doring Kindersley Ltd.

Pliego Carrasco, Fernando (1998). La cuestión urbana como base de la teoría sociológica. México: UNAM.

Quiroz RotTe, Héctor (2003). El malestar por la ciudad. México, D. F.: Fac. Arquitectura UNAM.

Rosas Mantecón, A. (2003). Conferencia Cátedra de la Ciudad. Ibero Golfo Centro.

Salazar Díaz, Lilian (2004). «Principales agentes y actores en el desarrollo de la ciudad de México entre 1921 y 1950». En Ciudad, Territorio y Patrimonio, materiales de investigación II. México: Universidad Iberoamericana Puebla.

Sayeg Helú, Jorge (1975). La creación del Distrito Federal. México: Colección Popular Ciudad de México.

SojA, E. W. (1996). Thirdplace: Journeys to Los Angeles and Other Real and Imagined Places. Oxford: Basil Badwell.

- (2000). Postmetropolis: Critical Studies of Cities and Regions. Oxford: Basil Bladwell. 
La construcción de lo guay en lo urbano.

Porras, Jeannette (2001). Condesa Hipódromo. México: Clío.

Tavares López, Edgar (1999). Colonia Hipódromo. México: Comité Editorial del Gobierno del Distrito Federal.

Trotiño, Miguel Ángel (2004). «Turismo y Desarrollo de las Ciudades Históricas Iberoamericanas. Desafíos y Oportunidades». En Ciudad, Territorio y Patrimonio, materiales de investigación II. México: Universidad Iberoamericana Puebla.

Viladeval i Guasch, Mireia (2001). Ciudad, Patrimonio y Gestión. México: Edit. BUAP. Secretaría de Cultura del Estado de Puebla.

Zamorano, Luis (2006). El rechazo ciudadano contra las políticas de redensificación. México: Fundación Metrópolis 2025.

Zárate Martín (1991). El Espacio Interior de la Ciudad. Madrid: Editorial Síntesis. 